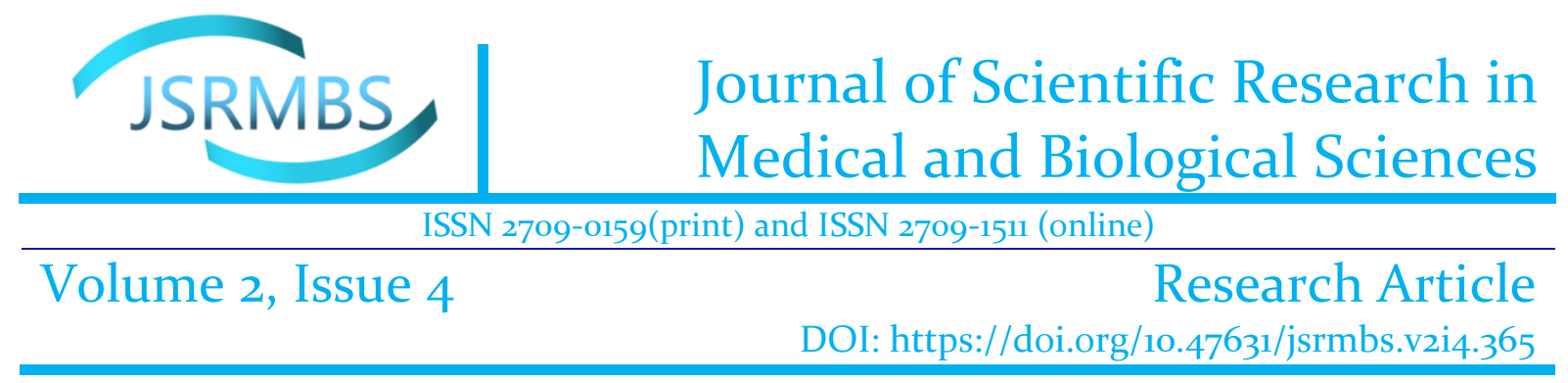

\title{
ASSESSMENT OF THYROID FUNCTIONS IN LATE PRETERM INFANTS OF MOTHERS ON ANTENATAL STEROIDS
}

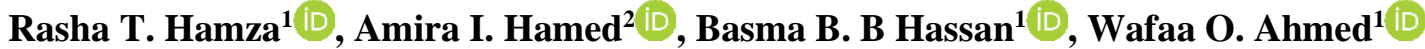 \\ ${ }^{1}$ Department of Pediatrics, Faculty of Medicine, Ain Shams University \\ ${ }^{2}$ Department of Clinical Pathology, Faculty of Medicine, Ain Shams University
}

\section{ARTICLE INFO}

Received: 12 October 2021

Revised: 06 November 2021

Accepted: 08 November 2021

Keywords:

Antenatal Steroids

Thyroid Function

Preterm

Corresponding Author:

Wafaa Osman Ahmed

Email:

wafaaosman83@gmail.com

Copyright (c) 2021 by author(s) and Journal of Scientific Research in Medical and Biological Sciences.

This work is licensed under the Creative Commons Attribution International License (CC BY 4.0).

http://creativecommons.org/licenses/ by/4.0/
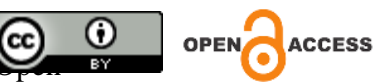

\begin{abstract}
Purpose: The study examined the effect of antenatal steroids on thyroid functions in late preterm infants on the third to the seventh day of life.

Patients and Methods: A comparative Cross-Sectional study was conducted on 75 neonates admitted to NICU in the first week of life. They were divided according to exposure to antenatal steroids into three groups. First group: exposed to complete course of ANS. Second group: exposed to partial course of ANS. The third group: not exposed to ANS. Serum samples were obtained from selected cases free T3, Free T4, and TSH levels in the third day of life, compared to the cut of levels currently available (the TSH reference range is (1.7 to $9.1 \mathrm{mU}$ per L), T4 should be greater than $10 \mathrm{mcg}$ per $\mathrm{dL}$ ). Using Eleusis and Cubase analyzers kits (Roche Diagnostics, Indianapolis, IN, USA) by ELISA (enzyme-linked immune sorbent assay) technique.

Results: The study showed that there were significantly higher serum T4 levels in group 1 that was exposed to a complete course compared to group 2 (partial course) and 3 (Third group). There were no significant differences in serum TSH, T3 levels between groups. The current study found a decreased incidence of the $R O P, N E C$ and BPD among group 1 as compared to the other two groups although was non statistically significant. In addition, the complete course of ANS had delayed the date of delivery $(P=0.04)$ as compared to the partial course in the current study.

Conclusion: Antenatal corticosteroids can influence thyroid function in late preterm infants as serum T4 was significantly higher in infants exposed to complete course compared to those who were exposed to partial course or did not receive antenatal corticosteroids.
\end{abstract}

\section{INTRODUCTION}

Preterm infants have an increased incidence of complications and mortality roughly proportional to the degree of prematurity. Infants born $>34$ weeks and $<37$ weeks are considered late preterm, infants born $>32$ weeks and $<34$ weeks are considered moderate preterm, infants born $>28$ weeks and $<32$ weeks are considered very preterm. Infants born $<28$ weeks are considered extremely preterm (Shapiro-Mendoza \& Lackritz, 2012). 
The use of antenatal steroids (ANS) has been associated with reductions in serious adverse outcomes of prematurity (Roberts et al., 2017). The administration of ANS is a very effective intervention in improving neonatal respiratory outcomes after preterm birth (Travers et al., 2017). The beneficial effect of ANS is dose-dependent, with the maximal benefit associated with a complete course of ANS (Chawla et al., 2016).

Postnatal thyroid function of preterm infants differs from that of term Infants. Thyroid dysfunction is common among premature Infants (Kaluarachchi et al., 2017). Neonatal thyroid function may be affected by excess iodide found in certain skin antiseptics and drugs eg. steroids (Brown, 1997)). There are limited studies of different steroid courses on thyroid function (Dinushan et al., 2018). The study aims to study the effect of antenatal steroids on thyroid functions in late preterm infants on the third to the seventh day of life

\section{METHODOLOGY}

This comparative cross-sectional study was conducted on 75 neonates admitted to NICU in 27 days of life.

\section{Subjects}

\section{Inclusion criteria:}

Late preterm infants between 34 weeks to 37 weeks by history and Ballard score (Ballard et al., 1991). They were divided according to exposure to antenatal steroids into three groups.

The first group (A): exposed to complete course of ANS.

The second group (B): exposed to a partial course of ANS.

The third group (C): not exposed to ANS.

Complete course of antenatal betamethasone consisting of two intramuscular $12 \mathrm{mg}$ doses that administered to mothers 24 hours apart, is recommended for pregnant women between 23 weeks and 33 weeks of gestation who are at risk of preterm delivery (The partial ANS group received 1 dose of betamethasone.

\section{Exclusion Criteria}

Full-term infants $>37$ weeks or preterm infants < 34 weeks, intrauterine growth retardation, multiple congenital anomalies or syndromes as Down syndrome, mothers with thyroid disorders, hypothalamic immaturity, protein-binding disturbances such as Thyroid binding globulin deficiency, central hypothyroidism, or primary hypothyroidism with delayed TSH elevation. Constant infusions of dopamine or high-dose glucocorticoids, midline facial abnormalities, hypoglycemia, microphallus.

Each newborn included in the study was subjected to the following:

\section{Detailed Medical History}

\section{Infant at Delivery}

- Apgar score and any resuscitation needed.

- Any abnormalities detected.

- Birth weight and head circumference. 
- Estimated gestational age.

- Vitamin K given.

- Placental weight.

- Infant since delivery:

- Time since delivery.

- Feeds given.

- Urine and meconium passed.

- Any clinical problems, e.g. hypothermia, respiratory distress, hypoglycemia.

- Contact between infant and mother.

\section{Maternal History}

- Gravidity, parity, screen (time and results), antenatal steroids (number of doses and timing), any medical or surgical history during or before pregnancy, problems with previous infants, e.g. neonatal jaundice, preterm delivery, congenital abnormalities.

- The home and socioeconomic status.

- Family history of congenital abnormalities.

- Maternal factors associated with newborn mortality eg. (maternal age, eclampsia, type 2 diabetes, urinary tract infection, positive serology to HIV, rupture of membranes, polyhydramnios, and premature separation of the placenta).

\section{Delivery}

Cause of preterm birth, any complication during delivery, or birth trauma.

\section{Clinical Examination which Covered}

\section{Systemic Clinical Examination}

- Weight, length, and head circumference.

- Neck examination, e.g. goiter.

- Fontanel examination.

Apgar Score (American College of Obstetricians and Gynecologists, 2015)

- Taken on the first and fifth minute of life and later if necessary.

- Determined by evaluating the newborn baby on five simple criteria

- (Appearance, pulse, grimace, activity, respiration) on a scale from zero to two, then summing up the five values thus obtained.

\section{Vital Data}

Heart rate, respiratory rate, temperature, and blood pressure using neonatal sphygmomanometer.

\section{Need For Respiratory Support.}

Ballard Score (Ballard et al., 991).

To ensure gestational age through maturity aging. 
Determine by evaluating the newborn on neuromuscular maturity (posture, square window, arm recoil, popliteal angle, and heel to ear) and physical maturity (skin, lanugo, planter surface, breast, eye, ear, genitalias men women) on a scale from 1 to 5 .

\section{Laboratory Analysis}

Serum samples were obtained from selected cases free T3, Free T4, and TSH levels in the third day of life, compared to the cut of levels currently available (the TSH reference range is (1.7 to $9.1 \mathrm{mU}$ per L), T4 should be greater than ( $10 \mathrm{mcg}$ per dL). Using Eleusis and Cubase analyzers kits (Roche Diagnostics, Indianapolis, IN, USA) by ELISA (enzyme-linked immune sorbent assay) technique. There was no storage of samples for further studies.

Confidentiality: All data were dealt with in complete confidentiality, and no one has the right to read your patient medical information except the main researcher. After the research is complete, you were informed regarding your patient's research results and also further information regarding your patient`s health status.

\section{RESULTS AND DISCUSSION}

Table 1. Comparison of neonatal clinical characteristics according to exposure to antenatal steroids

\begin{tabular}{|c|c|c|c|c|c|c|c|c|}
\hline & & & \multicolumn{3}{|c|}{ Studied group } & \multirow{2}{*}{$\begin{array}{c}\mathrm{X}^{2} / \text { Exact } \\
\text { Fischer }\end{array}$} & \multirow{2}{*}{$\begin{array}{c}\mathbf{P} \\
\text { value }\end{array}$} & \multirow[t]{2}{*}{ Sig. } \\
\hline \multirow{5}{*}{ SEX } & & & $\mathbf{A}$ & B & C & & & \\
\hline & Male & N. & 14 & 8 & 12 & 0.753 & 0.686 & NS \\
\hline & & $\%$ & $46.7 \%$ & $53.3 \%$ & $40.0 \%$ & & & \\
\hline & Female & N. & 16 & 7 & 18 & & & \\
\hline & & $\%$ & $53.3 \%$ & $46.7 \%$ & $60.0 \%$ & & & \\
\hline \multirow[t]{4}{*}{5 min Apgar } & No & N. & 24 & 9 & 20 & 2.316 & 0.314 & NS \\
\hline & & $\%$ & $80.0 \%$ & $60.0 \%$ & $66.7 \%$ & & & \\
\hline & Yes & N. & 6 & 6 & 10 & & & \\
\hline & & $\%$ & $20.0 \%$ & $40.0 \%$ & $33.3 \%$ & & & \\
\hline \multirow[t]{4}{*}{ SGA } & No & $\mathrm{N}$. & 20 & 14 & 30 & 14.276 & 0.001 & HS \\
\hline & & $\%$ & $66.7 \%$ & $93.3 \%$ & $100.0 \%$ & & & \\
\hline & Yes & $\mathrm{N}$. & 10 & 1 & 0 & & & \\
\hline & & $\%$ & $33.3 \%$ & $6.7 \%$ & $0.0 \%$ & & & \\
\hline \multirow[t]{4}{*}{ Surfactant } & No & $\mathrm{N}$. & 10 & 1 & 2 & 8.933 & 0.011 & $\mathrm{~S}$ \\
\hline & & $\%$ & $33.3 \%$ & $6.7 \%$ & $6.7 \%$ & & & \\
\hline & Yes & $\mathrm{N}$. & 20 & 14 & 28 & & & \\
\hline & & $\%$ & $66.7 \%$ & $93.3 \%$ & $93.3 \%$ & & & \\
\hline \multirow[t]{4}{*}{ Levothyroxine } & No & $\mathrm{N}$. & 29 & 13 & 24 & 3.977 & 0.137 & NS \\
\hline & & $\%$ & $96.7 \%$ & $86.7 \%$ & $80.0 \%$ & & & \\
\hline & Yes & N. & 1 & 2 & 6 & & & \\
\hline & & $\%$ & $3.3 \%$ & $13.3 \%$ & $20.0 \%$ & & & \\
\hline \multirow[t]{4}{*}{ IVH } & No & N. & 29 & 11 & 26 & 5.240 & 0.073 & NS \\
\hline & & $\%$ & $96.7 \%$ & $73.3 \%$ & $86.7 \%$ & & & \\
\hline & Yes & N. & 1 & 4 & 4 & & & \\
\hline & & $\%$ & $3.3 \%$ & $26.7 \%$ & $13.3 \%$ & & & \\
\hline \multirow[t]{4}{*}{ Dopamine } & No & $\mathrm{N}$. & 24 & 11 & 26 & 1.230 & 0.541 & NS \\
\hline & & $\%$ & $80.0 \%$ & $73.3 \%$ & $86.7 \%$ & & & \\
\hline & Yes & $\mathrm{N}$. & 6 & 4 & 4 & & & \\
\hline & & $\%$ & $20.0 \%$ & $26.7 \%$ & $13.3 \%$ & & & \\
\hline
\end{tabular}

Small for gestational age (SGA), Intraventricular hemorrhage (IVH)

Hint: $(P<0.05$ is significant $)$ 
The APGAR 5- min score was $<7$ in 29.3 of neonates $(20.0 \%, 40 \%, 33.3 \%)$ in A,B,C groups $(\mathrm{P}$-value $=0.314)$ which wasn't statistically significant. On the other hand, a surfactant was administered to $82.7 \%$ of them $(66.7 \%, 93.3 \%, 93.3 \%)$ that relates to A,B,C groups (P-value = 0.011 ) which wasn't statistically significant.

About $12 \%$ of neonates have received Levo thyroxin $(3.3 \%, 13.35,20 \%)$ that relates to A,B,C groups $(\mathrm{P}$-value $=0.137)$ which wasn't statistically significant. About $12 \%$ of them experienced Intraventricular hemorrhage (IVH) $(3.3 \%, 26.7 \%, 13.3 \%)$ that relates to A,B,C groups $(\mathrm{P}$-value $=0.073$ ) which wasn't statistically significant. The difference among the groups wasn't statistically significant.

Table 2. Comparison of infant age, birth weight and maternal age according to exposure to antenatal steroids

\begin{tabular}{cccccccc}
\hline \multirow{2}{*}{ Gestational Age } & & N & Mean & SD & F & P value & Sig. \\
\cline { 3 - 8 } & A & 30 & 35.20 & 0.997 & 1.019 & 0.366 & NS \\
\multirow{2}{*}{ Birth weight } & B & 15 & 35.20 & 1.082 & & & \\
\multirow{5}{*}{ MATERNAL AGE } & C & 30 & 35.53 & 0.937 & & & \\
& A & 30 & $1,800.40$ & 373.907 & 13.804 & 0.000 & HS \\
& B & 15 & $2,152.87$ & 365.991 & & & \\
& C & 30 & $2,243.03$ & 279.980 & & & \\
& A & 30 & 25.97 & 3.891 & 0.132 & 0.876 & NS \\
& B & 15 & 25.93 & 4.367 & & & \\
\hline
\end{tabular}

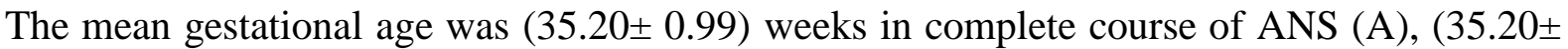
$0.99)$ weeks in partial course of ANS (B) and ((35.53 0.99$)$ weeks in No ANS (p-value = 0.366). As indicated above, $45.3 \%$ were males and $54.7 \%$ were females.

The mean birth weight was $(1,800.40 \pm 397.6)$ gm versus $(2,152.87 \pm 397.6) g m$ versus $(2,243.03 \pm 397.6) \mathrm{gm}$ in $\mathrm{A}, \mathrm{B}, \mathrm{C}$ groups ( $\mathrm{p}$-value $=0.001)$ relates to group $\mathrm{A}$, it is highly significant $(\mathrm{p}$-value $=0.000)$ relates to group $\mathrm{B}$, it is highly significant $(\mathrm{p}$-value $=0.401)$ relates to group $\mathrm{C}$, it is Non-significant.

Table 3. Comparison of maternal history according to exposure to antenatal steroids

\begin{tabular}{|c|c|c|c|c|c|c|c|c|}
\hline \multirow{5}{*}{ PARITY } & \multirow{4}{*}{1.0} & & \multicolumn{3}{|c|}{ Studied group } & \multirow{2}{*}{$\begin{array}{l}\mathbf{X}^{2} / \text { Exact } \\
\text { Fischer }\end{array}$} & \multirow{2}{*}{$\begin{array}{c}\text { P- } \\
\text { value }\end{array}$} & \multirow[t]{2}{*}{ Sig. } \\
\hline & & & A & B & C & & & \\
\hline & & N. & 8 & 5 & 6 & 2.084 & 0.720 & NS \\
\hline & & $\%$ & $26.7 \%$ & $33.3 \%$ & $20.0 \%$ & & & \\
\hline & 2.0 & N. & 18 & 9 & 22 & & & \\
\hline & & $\%$ & $60.0 \%$ & $60.0 \%$ & $73.3 \%$ & & & \\
\hline & 3.0 & N. & 4 & 1 & 2 & & & \\
\hline & & $\%$ & $13.3 \%$ & $6.7 \%$ & $6.7 \%$ & & & \\
\hline DELIVERY & NVD & N. & 12 & 5 & 12 & 0.225 & 0.894 & NS \\
\hline MODE & & $\%$ & $40.0 \%$ & $33.3 \%$ & $40.0 \%$ & & & \\
\hline & $\mathrm{CS}$ & N. & 18 & 10 & 18 & & & \\
\hline & & $\%$ & $60.0 \%$ & $66.7 \%$ & $60.0 \%$ & & & \\
\hline SINGLE OR & 1.0 & N. & 20 & 12 & 20 & 1.003 & 0.606 & NS \\
\hline TWIN & & $\%$ & $66.7 \%$ & $80.0 \%$ & $66.7 \%$ & & & \\
\hline & 2.0 & N. & 10 & 3 & 10 & & & \\
\hline & & $\%$ & $33.3 \%$ & $20.0 \%$ & $33.3 \%$ & & & \\
\hline Preeclampsia & No & N. & 26 & 14 & 28 & 0.945 & 0.623 & NS \\
\hline & & $\%$ & $86.7 \%$ & $93.3 \%$ & $93.3 \%$ & & & \\
\hline
\end{tabular}




\begin{tabular}{ccccccccc}
\hline & Yes & N. & 4 & 1 & 2 & & & \\
PROM & & $\%$ & $13.3 \%$ & $6.7 \%$ & $6.7 \%$ & & \\
& No & N. & 14 & 10 & 15 & 1.683 & 0.431 & NS \\
& & $\%$ & $46.7 \%$ & $66.7 \%$ & $50.0 \%$ & & & \\
Yes & N. & 16 & 5 & 15 & & & \\
& & $\%$ & $53.3 \%$ & $33.3 \%$ & $50.0 \%$ & & & \\
& No & N. & 26 & 15 & 30 & 6.338 & 0.042 & $\mathrm{~S}$ \\
& & $\%$ & $86.7 \%$ & $100.0 \%$ & $100.0 \%$ & & & \\
Thyroid & Yes & N. & 4 & 0 & 0 & & & \\
& & $\%$ & $13.3 \%$ & $0.0 \%$ & $0.0 \%$ & & & \\
& No & N. & 28 & 15 & 28 & 1.056 & 0.590 & NS \\
& & $\%$ & $93.3 \%$ & $100.0 \%$ & $93.3 \%$ & & & \\
HTN & Yes & N. & 2 & 0 & 2 & & & \\
& & $\%$ & $6.7 \%$ & $0.0 \%$ & $6.7 \%$ & & & \\
& No & N. & 24 & 14 & 30 & 7.248 & 0.027 & $\mathrm{~S}$ \\
& & $\%$ & $80.0 \%$ & $93.3 \%$ & $100.0 \%$ & & & \\
& Yes & N. & 6 & 1 & 0 & & & \\
& & $\%$ & $20.0 \%$ & $6.7 \%$ & $0.0 \%$ & & & \\
& No & N. & 24 & 13 & 26 & 0.595 & 0.743 & NS \\
& & $\%$ & $80.0 \%$ & $86.7 \%$ & $86.7 \%$ & & & \\
& Yes & N. & 6 & 2 & 4 & & & \\
\hline
\end{tabular}

As shown in the previous table, we concluded that the mean maternal age was (25.97 years Versus 25.93 years versus 25.47 years) in $\mathrm{A}, \mathrm{B}, \mathrm{C}$ groups ( $\mathrm{p}$-value $=0.876$ ) which weren't statistically significant.

While $25.3 \%$ in Para one $(26.7 \%, 33.3 \%, 20.0 \%)$ that relates to A,B,C groups, but the Para two patients were $65.3 \%(60 \%, 60 \%, 73.3 \%)$ that relates to $\mathrm{A}, \mathrm{B}, \mathrm{C}$ groups, and the Para three patients were $9.3 \%(13.3 \%, 6.7 \%, 6.7 \%$ that relates to $\mathrm{A}, \mathrm{B}, \mathrm{C}$ groups ( $\mathrm{p}$-value $=0.720)$ which wasn't statistically significant. About $61.3 \%$ of patients had cut section $(60 \%, 66.7 \%, 60 \%)$ that relates to A,B,C groups ( $\mathrm{p}$-value $=0.894$ ) which wasn't statistically significant.

About $38.7 \%$ of them didn't report surgical history $(40 \%, 33.3 \%, 40 \%)$ that relates to A,B,C groups. Only the difference between A,B,C groups $(13.3 \%, 10.0 \%, 10.0 \%)$ as respectively, regarding Chorioamnionitis was clinically significant $(\mathrm{P}$-value $=0.042)$.

Table 4. Correlation between Free T4 (mcg/dl) and factors in neonatal clinical characteristics

\begin{tabular}{ccccccc}
\hline & Parity & $\begin{array}{c}\text { Mean Free } \\
\text { T4 } \\
\text { (mcg/dl) }\end{array}$ & SD & F/ T test & P value & Sig. \\
\cline { 2 - 7 } Sufactant & No & 11.3 & 1.2 & 2.622 & 0.110 & NS \\
& Yes & 10.8 & 1.1 & & & \\
Levothyroxine & No & 11.1 & 0.9 & 25.939 & 0.000 & HS \\
& Yes & 9.3 & 1.5 & & & \\
IVH & No & 10.9 & 1.1 & 0.089 & 0.766 & NS \\
& Yes & 10.8 & 1.2 & & & \\
Dopamine & No & 10.8 & 1.2 & 1.734 & 0.192 & NS \\
& Yes & 11.2 & 0.9 & & & \\
\hline
\end{tabular}

As regarding this previous table, there was a highly significant relation between free T4 level and the need for Levothyroxine. Free T4 $($ Mean $=11.1)$ in neonates indicates that they didn't need Levothyroxine higher than its level $($ Mean $=9.3)$ in neonates had taken. $*$ P-value $=0.000$ : Highly significant. 
There was no relation between free T4 and Surfactant, Levothyroxine, IVH, and Dopamine. Pvalue $>0.05$ : Non-significant.

Table 5. Comparison of laboratory analysis according to exposure to antenatal steroids

\begin{tabular}{|c|c|c|c|c|c|c|c|}
\hline & & $\mathbf{N}$ & Mean & SD & $\mathbf{F}$ & $P$ value & Sig. \\
\hline $\mathrm{Hb}$ & A & 30 & 15.077 & 1.3510 & 0.997 & 0.374 & NS \\
\hline \multirow[t]{2}{*}{$(\mathrm{gm} / \mathrm{dl})$} & B & 15 & 14.520 & 1.4194 & & & \\
\hline & $\mathrm{C}$ & 30 & 14.743 & 1.2445 & & & \\
\hline PTT & A & 30 & 73.43 & 9.164 & 131.137 & 0.000 & HS \\
\hline \multirow[t]{2}{*}{ (seconds) } & B & 15 & 107.07 & 8.819 & & & \\
\hline & $\mathrm{C}$ & 30 & 100.87 & 5.513 & & & \\
\hline WBC & A & 30 & 15.200 & 3.7470 & 0.077 & 0.926 & NS \\
\hline \multirow[t]{2}{*}{$\left(10^{9} / \mathrm{L}\right)$} & B & 15 & 15.067 & 3.2660 & & & \\
\hline & $\mathrm{C}$ & 30 & 14.850 & 3.3013 & & & \\
\hline PT & A & 30 & 10.300 & 0.9340 & 121.160 & 0.000 & HS \\
\hline \multirow[t]{2}{*}{ (seconds) } & B & 15 & 14.493 & 0.9603 & & & \\
\hline & $\mathrm{C}$ & 30 & 12.957 & 0.8811 & & & \\
\hline Lactate & A & 30 & 1.5040 & 0.09474 & 4.941 & 0.003 & HS \\
\hline \multirow[t]{2}{*}{$(\mathrm{mmol} / \mathrm{L})$} & B & 15 & 1.5620 & 0.10544 & & & \\
\hline & $\mathrm{C}$ & 30 & 1.5817 & 0.09745 & & & \\
\hline \multirow{6}{*}{$\begin{array}{c}\text { Platelet } \\
\text { count } \\
\left(10^{9} / \mathrm{L}\right) \\
\mathrm{PCo} 2 \\
(\mathrm{mmHg})\end{array}$} & A & 30 & 276.60 & 52.642 & 97.843 & 0.000 & HS \\
\hline & B & 15 & 153.60 & 15.711 & & & \\
\hline & $\mathrm{C}$ & 30 & 156.90 & 21.064 & & & \\
\hline & A & 30 & 42.8067 & 1.31581 & 87.273 & 0.000 & HS \\
\hline & B & 15 & 45.6060 & 1.21675 & & & \\
\hline & $\mathrm{C}$ & 30 & 47.6213 & 1.58936 & & & \\
\hline \multirow{3}{*}{$(\mathrm{Meq} / \mathrm{L})$} & A & 30 & 23.0007 & 0.67611 & 91.193 & 0.000 & HS \\
\hline & B & 15 & 21.0527 & 0.60060 & & & \\
\hline & C & 30 & 19.8673 & 1.18203 & & & \\
\hline
\end{tabular}

Hemoglobin Concentration (Hb), Partial Thromboplastin Time (PTT), White Blood Cell Count (WBC), prothrombin time (PT), partial pressure of carbon dioxide (PCO2), Bicarbonate(HCO3).

As regarding this table, there was a relationship between these laboratory results (PTT, PT, Lactate, Platelet count, $\mathrm{PCO} 2$, and $\mathrm{HCO} 3$ ) and exposure to antenatal steroids; $\mathrm{P}$-value <0.05: highly significant. While there was no relation between $\mathrm{Hb}$, WBCS results and antenatal steroids; *P-value >0.05: Non-significant.

In the preterm baby, the thyroid axis is immature, with reduced hypothalamic TRH production and secretion, an immature response of the thyroid gland to TSH, an inefficient capacity of the follicular cell of the thyroid to organify iodine, and a low capacity to convert T4 into active T3. Hence, when a baby is born preterm, the level of T4 is lower than that of term babies and correlates with gestational age and birth weight. Levels of TSH and T3 are normal to low, free T4 concentrations are also low, and thyroglobulin levels are high (reflecting increased thyroid gland production of poorly iodinated thyroid hormone precursor). Responses of TSH and T4 to TRH are normal, reflecting that the site of immaturity is the hypothalamus. In addition, hypothyroxinaemia is in part secondary to reduced levels of thyroid binding globulin. These data would suggest that the hypothyroxinaemia of prematurity is physiological.

In this study, we evaluate the comparative effects of no ANS, partial ANS, and complete ANS on thyroid function at day 3 of life (DOL) among preterm infants born after 30 weeks of gestation. We hypothesize that infants exposed to a complete course of ANS had better thyroid hormone function compared to no ANS and partial ANS groups. 
The study involved 75 neonates that were divided as follows; 30 neonates received a complete course of antenatal steroids(group 1), 15 neonates received a partial course of antenatal steroids(group2) and 30 matched controls. The cases and controls were sex and agematched(group3), although the neonates of both groups 1,2 were slightly younger than the control, there was no statistical difference. On the contrary (Simonetta et al. (2007)) found a significant difference in gestational age at birth between-group who received ANS and non $(\mathrm{p}<0.001)$, being lower in the ANS group. Regarding the weight of the group who received the complete course of $\mathrm{AN}$, it was significantly lower as compared to both other groups. This can be explained by the underlying comorbidities that led to preterm labor and encouraged the obstetrician to give the complete course of steroids. Similarly, Simonetta et al. (2007) found that mean birth weight $(1375+/-454 \mathrm{~g}$ versus $1625+/-580 \mathrm{~g}, \mathrm{p}<0.001)$ was significantly lower in the ANS than in non-ANS respectively

The complete course of ANS had delayed the date of delivery $(\mathrm{P}=0.04)$ as compared to the partial course in the current study. The need for resuscitation in the delivery room as expressed by the APGAR score showed a significant difference among the three groups and that steroids could have an effect on resuscitation need. Mean gestational age at delivery, 1- and 5-min Apgar score and length of admission to delivery in the present study were higher in the group of complete ANS course as compared to the other 2 groups. This comes in agreement of 11 . Hanaoka et al, (2020) who found that the ANS group had higher APGAR scores at 1, 5 minutes.

The incidence of hemodynamic instability and the consequent need for cardiac inotropic support could reflect the effect of steroids on the maturation of the preteen neonate and reflect the good function of the thyroid, so we evaluated the vital data of the neonates and subsequent need for inotropes and found that the complete ANS group needed less resuscitation (p0.02) and this comes in agreement of Hanaoka et al, (2020) who found that the ANS group needed less cardiac support although was statistically insignificant $(\mathrm{p}=0.39)$

Of note, all our studied groups were euthyroid and none needed replacement. Thyroid function status among the ANS groups is compared to the other two groups, there was no difference in the FT3 and TSH levels between the groups, interestingly, Dinushan et al. 2018 found that both T4 and TSH was not different among the corresponding groups, but found that T3 was higher in the group with a complete course of ANS.

Free T4 level was significantly higher in group 1 (complete ANS course) than group 2 and 3 in our studied group. This could be explained by the cumulative effect of the repeated doses of antenatal steroids.

Though was non statistically significant; Free T3 was show slightly higher values in both groups (complete and partial course) exposed to ANS, but it could reflect the effect of ANS use. This was in line with Osathanoudh et al. (1978) and Dinushan et al. (2018) who found a mean concentration of T3 plasma of ANS treated patients were higher than those of the control group, however, they used dexamethasone. Also, many animal studies Polk et al. (1995) and. Ikegami et al. (1991) demonstrated increased circulating levels of T3 after ANS administration. Another study by Franklin et al. (1986) that measured thyroid function tests in 97 preterm neonates at birth and on three following occasions; 5, 10, and 15 days of age and concluded that treatment with steroids prenatally had no apparent effect on thyroid function at birth or postnatally.

The current study showed that the mean TSH level was 4.36 and 4.24 in both complete and non-ANS courses, in line with our results, the study by Hanaoka et al. (2020) showed that the TSH level was 6.2 and 7.6(mIU/L) respectively. They studied a group of 99 very low birth weight neonates ( $<34$ weeks' gestational age) and divided into a complete group $(n=49)$ whose 
mothers completed two doses of betamethasone and a group with no ANS ( $n=50)$ who were not exposed to any ANS. They also found FT4 was 14.2 and $13.5(\mathrm{pmol} / \mathrm{L})$ in respective groups.

The decrease in TSH by ANS might be considered as an unfavorable effect on the HPT axis, as glucocorticoids are known to have suppressive effects on this and can cause hypothyroidism, but in our study, the TSH level was in the normal range and the serum FT4 level was significantly different among the three studied groups, and we concluded that there was no evidence of suppression of FT4 by ANS, in acceptance with our results Hanaoka et al. (2020) who found no difference in the serum FT4 level and TSH between the two groups( complete and non-ANS receiver), and no suppression of FT4 by ANS. Therefore, we consider that ANS therapy caused maturation of the HPT axis but not its suppression.

The need for cardiorespiratory support could be considered as an explanation for increased risk of thyroid dysfunction in no ANS group, where $50 \%$ of neonates who didn't receive ANS needed resuscitation in the delivery room with subsequent need for respiratory support, while the complete ANS course followed by the incomplete course needed resuscitation, this comes in line with Franklin et al. (1986) who reported that infants with RDS had significantly lower FT4, and F T3 values. In the current study, a higher proportion of infants in no ANS group received exogenous surfactant administration compared to the complete ANS group indicating greater severity of RDS in no ANS group. On the contrary, Simonetta et al. (2007) found that delivery room intubation and respiratory distress syndrome were more frequent in the ANS group and that the length of stay was also significantly longer in this group. Also, this comes in agreement with Hanaoka et al, (2020) who found that the ANS group needed less resuscitation and less servant administration.

The current study considered the neonatal morbidities of prematurity and considered the severe intracranial hemorrhage as (grade 3-4) by using Papile's grading system and medical or surgical necrotizing enterocolitis (stage $\geq 2$ ) by using the modified Bell's criteria. Infants diagnosed as having suspected necrotizing enterocolitis (stage 1) were not included. We defined severe retinopathy of prematurity (stage $\geq 3$ or treated with ablation/antivascular endothelial growth factor) by using the International Classification of Retinopathy of Prematurity and bronchopulmonary dysplasia (BPD)by using the traditional definition of treatment with supplemental oxygen or respiratory support at 36 weeks' postmenstrual age.

As a secondary outcome, intraventricular hemorrhage was lower among neonates who received complete ANS course, this comes in line with the cohort study by the Neonatal Research Network Generic Database (NICHD ) registry that reported that complete ANS and partial ANS courses were associated with lower rates of death and neurodevelopmental consequences compared to the no ANS group, they conclude that these effects are mediated through a reduction in rates of severe intracranial hemorrhage and/or cystic periventricular leukomalacia in the neonatal period (Chawla et al., 2016). Also, Liggins et al., conducted the first randomized controlled trial of antenatal betamethasone, showing downward mortality and lower risks of RDS in infants of treated mothers compared to controls and the need for respiratory support. In that study, four of the infants of control mothers had IVH, compared to none of the infants of steroid-treated mothers. Although this difference was not statistically significant, this finding raised the possibility that antenatal steroid use might reduce the incidence of IVH. Also, a Cochrane review in 2006 consisted of a meta-analysis of randomized trials that demonstrated a reduced risk of IVH and found a relative risk of $0.54,95 \%$ confidence interval 0.43 to 0.69 when treatment with antenatal steroids occurred (Roberts, Dalziel, nd). Wei et al. (2016) found also that antenatal steroid use was associated with a reduction in incidence of any grade of intraventricular hemorrhage (odds ratio $=0.51,95 \%$ confidence interval: $0.45,0.58$ ) and a reduction in incidence of severe intraventricular hemorrhage (odds ratio $=0.62,95 \%$ 
confidence interval: 0.57, 0.67). Also, this comes in agreement of Hanaoka et al, 2020 (11) who found that the ANS group had less Intraventricular hemorrhage.

The current study found a decreased incidence of the ROP, NEC and BPD among group 1 as compared to the other two groups although was non statistically significant. Nonetheless, it is worth mentioning that this comes in agreement with Simonetta et al. (2007) who found that major neonatal morbidity outcomes were lower in survivors of early preterm but no differences regarding survival, neonatal morbidity, need for and duration of mechanical ventilation, oxygen therapy among intermediate and late preterm neonates.

Neonates of group 1 in the present study, had slightly but insignificantly higher WBC, HB(P > $0.05)$ as compared to other groups. This could be explained by many studies as an association to preterm labor and not due to concomitant steroids use. Moreover, the current study excluded women with signs of infection (maternal temperature $>37.5^{\circ} \mathrm{C}$ ), positive urine culture and vaginal bleeding due to placenta previa or placental abruption. Also the mechanisms by which corticosteroids might predispose to infection are not clear and several studies have shown little or no increase in the incidence of infection among corticosteroid-treated patients compared with control (Andersson et al., 1986; Mukwaya, 1988). The study by Vankayalapati et al. (1998) who investigate the effect of prenatal steroids on postnatal blood counts and stated that there were no statistical differences in total white blood cell counts or absolute neutrophil counts between the groups on admission or at any time from day 1-3. However, nucleated red blood cell counts (per $100 \mathrm{wbc}$ ) were found to be higher in the control group as compared to the steroid group on admission and on days 1-3 (admission: $78 \pm 129$ vs $40 \pm 83$, p <.001, day 1: $58 \pm 146$ vs $36 \pm 129, \mathrm{p}=.007$, day $2: 58 \pm 167$ vs $31 \pm 119, \mathrm{p}=.002$, day $3: 49 \pm 139$ vs $18 \pm 53$, $\mathrm{p}=.002)$.

Co2 was significantly lower while the venous bicarbonate level was higher among group 1 as compared to the other two groups. Partial thromboplastin time and prothrombin time were significantly lower in group 1 as compared to the two other groups, this could reflect the decrease in the incidence of IVH.

Platelets count were significantly higher among group 1 as compared to the other two groups. This could be explained by the effect of steroids on the megakaryocytic series. In acceptance with our results; Vankayalapati et al (21) stated that Platelet counts were higher on admission and each day from day 1 through 3 , in the steroid group as compared to the control group (admission: $228 \pm 67 \mathrm{~mm} 3$ vs $200 \pm 73 \mathrm{~mm} 3$, p <.001; day 1: $222 \pm 73 \mathrm{~mm} 3$ vs $195 \pm 73 \mathrm{~mm} 3$, p $<.001$, day 2: $219 \pm 85 \mathrm{~mm} 3$ vs $195 \pm 93 \mathrm{~mm} 3, \mathrm{p}=.002$, and day $3: 231 \pm 151 \mathrm{~mm} 3$ vs $192 \pm 88$, $\mathrm{mm} 3 \mathrm{p}<.001)$. In the current study, infants below the 10th percentile of weight for their gestational age were classified as being small for gestational age while those above the 10th percentile were classified as normal for gestational age according to the CPQCC manual of definitions, (2013). SGA was more in group 1 was significantly expressed in group 1 as compared to group $2(\mathrm{p}=0.001)$ and this could reflect the predisposing factors that led to prematurity as preeclampsia ( present in $13.3 \%$ in group 1 versus $6.7 \%$ in group 2 ), twinning $(33.3 \%$ versus $20 \%)$, premature rupture of membranes $(53.3 \%$ versus $33.3 \%)$ and Chorioamnionitis (13.3\% in group 1). On the other side, Hanaoka et al., (2020) found a nonsignificant difference regarding the incidence of SGA between the two groups (received ANS and non) $(\mathrm{P}=0.06)$. The study revealed a positive association of complete course of antenatal steroids and total thyroxin level. 


\section{CONCLUSION}

Antenatal corticosteroids can influence thyroid function in late preterm infants as serum T4 was significantly higher in infants exposed to complete course compared to those who were exposed to partial course or did not receive antenatal corticosteroids.

\section{REFERENCES}

American College of Obstetricians and Gynecologists (2015). The Apgar score. Committee Opinion No. 644. Obstet Gynecol, 126, e52-e55. https://doi.org/10.1097/AOG.0000000000001108

Andersson, R., Malmvall, B. E., \& Bengtsson, B. A.. (1986). Long-term corticosteroid treatment in giant cell arteritis. Acta medica Scandinavica, 220(5), 465-469. https://doi.org/10.1111/j.09546820.1986.tb02796.x

Ballard, J. L., Khoury, J. C., Wedig, K. L., Wang, L., Eilers-Walsman, B. L., \& Lipp, R. (1991). New Ballard Score, expanded to include extremely premature infants. The Journal of pediatrics, 119(3), 417-423. https://doi.org/10.1016/s0022-3476(05)82056-6

Brown, R. S. (1997). Thyroid Disease in Infancy, Childhood, and Adolescence. In Diseases of the thyroid (pp. 81-102). Humana Press, Totowa, NJ.

Chawla, S., Natarajan, G., Shankaran, S., Pappas, A., Stoll, B. J., Carlo, W. A., ... \& National Institute of Child Health and Human Development Neonatal Research Network. (2016). Association of neurodevelopmental outcomes and neonatal morbidities of extremely premature infants with differential exposure to antenatal steroids. JAMA pediatrics, 170(12), 1164-1172. https://doi.org/10.1001/jamapediatrics.2016.1936

Costa, S., Zecca, E., De Luca, D., De Carolis, M. P., \& Romagnoli, C. (2007). Efficacy of a single dose of antenatal corticosteroids on morbidity and mortality of preterm infants. European Journal of Obstetrics \& Gynecology and Reproductive Biology, 131(2), 154157.https://doi.org/10.1016/j.ejogrb.2006.05.006

CPQCC Network Database Manual of Definitions for Infants Born in 2013. Available at: http://cpqcc.org/data/cpqcc_downloads

Dinushan C, Kaluarachchi, Qianqian Zhao \&Tarah T. Colaizy, (2018). Antenatal steroids and thyroid hormone function in preterm infants. Journal of Perinatology. 38, 1466-1470. https://doi.org/10.1038/s41372-018-0225-5

Franklin, R. C., Purdie, G. L., \& O'Grady, C. M. (1986). Neonatal thyroid function: prematurity, prenatal steroids, and respiratory distress syndrome. Archives of disease in childhood, 61(6), 589-592. https://doi.org/10.1136/adc.61.6.589

Hanaoka, S., Iwanaga, K., Tomotaki, S., Niwa, F., Takita, J., \& Kawai, M. (2020). Antenatal corticosteroids for threatened labour facilitate thyroid maturation among preterm neonates. Clinical Endocrinology, 93(5), 613-619. https://doi.org/10.1111/cen.14272

Ikegami, M. A. C. H. I. K. O., Polk, D. A. N. I. E. L., Tabor, B. A. N. N. I. E., Lewis, J. A. M. E. S., Yamada, T. A. K. A. K. O., \& Jobe, A. L. A. N. (1991). Corticosteroid and thyrotropinreleasing hormone effects on preterm sheep lung function. Journal of applied physiology, 70(5), 2268-2278. https://doi.org/10.1152/jappl.1991.70.5.2268

Kaluarachchi, D., Colaizy, T., Pesce, L., Tansey, M., \& Klein, J. (2017). Thyroid dysfunction in very low birth weight premature infants. Journal of Perinatol, 37, 277-282. https://doi.org/10.3345/kjp.2015.58.6.224

Mukwaya, G. (1988). Immunosuppressive effects and infections associated with corticosteroid therapy. The Pediatric infectious disease journal, 7(7), 499. https://doi.org/10.1097/00006454-198807000-00011

Osathanondh, R., Chopra, I. J., \& Tulchinsky, D. (1978). Effects of dexamethasone on fetal and maternal thyroxine, triiodothyronine, reverse triiodothyronine, and thyrotropin levels. The Journal of Clinical Endocrinology \& Metabolism, 47(6), 1236-1239. https://doi.org/10.1210/jcem-47-6-1236

Polk, D. H., Ikegami, M., Jobe, A. H., Newnham, J., Sly, P., Kohen, R., \& Kelly, R. (1995). Postnatal lung function in preterm lambs: Effects of a single exposure to betamethasome and thyroid hormones. American journal of obstetrics and gynecology, 172(3), 872-881. 
https://doi.org/10.1016/0002-9378(95)90014-4

Roberts, D., Brown, J., Medley, N., \& Dalziel, S. R. (2017). Antenatal corticosteroids for accelerating fetal lung maturation for women at risk of preterm birth. Cochrane database of systematic reviews, 19(3).CD004454. https://doi.org/10.1002/14651858.CD004454.pub3

Shapiro-Mendoza, C. K., \& Lackritz, E. M. (2012). Epidemiology of late and moderate preterm birth. In Seminars in Fetal and Neonatal Medicine, 17, (3), 120-125. WB Saunders. https://doi.org/10.1016/j.siny.2012.01.007

Travers, C. P., Clark, R. H., Spitzer, A. R., Das, A., Garite, T. J., \& Carlo, W. A. (2017). Exposure to any antenatal corticosteroids and outcomes in preterm infants by gestational age: prospective cohort study. BMJ, 356. https://doi.org/10.1136/bmj.j1039

Vankayalapati, S. P., Paul, D. A., Leef, K. H., \& Stefano, J. L. (1998). Antenatal Steroids: Do They Affect Postnatal Blood Counts?† 1170. Pediatric Research, 43(4), 201-201. https://doi.org/10.1203/00006450-199804001-01191

Wei, J. C., Catalano, R., Profit, J., Gould, J. B., \& Lee, H. C. (2016). Impact of antenatal steroids on intraventricular hemorrhage in very-low-birth-weight infants. Journal of Perinatology, 36(5), 352-356. https://doi.org/10.1038/jp.2016.38 